\title{
Risk Governance: Application to Urban Challenges
}

\author{
Ortwin Renn $^{1} \cdot$ Andreas Klinke $^{1,2} \cdot$ Pia-Johanna Schweizer ${ }^{1}$
}

Published online: 17 December 2018

(C) The Author(s) 2018

\begin{abstract}
Urban areas face multiple risks: they range from natural hazard-induced disasters, fires, and building code violations to social risks such as vandalism, crime, and social disorientation, among others. These risks often interact with each other and cannot be dealt with in isolation. As a means to identify, assess, and manage multiple risks, the concept of "risk governance" has been developed, which promises to provide integrative and comprehensive tools to deal with the many manifestations of risks. In this article, risk governance concept has been specifically applied to complex risk situations in urban areas. The concept of risk governance pertains to the many ways in which multiple actors, individuals and institutions, public and private, deal with risks. It includes formal institutions and regimes and informal arrangements. The article first develops an adaptive and integrative model of risk governance and applies this model to the urban environments. After a short summary of the roots of risk governance, key concepts, such as simple, uncertain, complex, and ambiguous risks, are discussed. The main emphasis is on each of the five phases of risk governance: pre-estimation, interdisciplinary assessment, risk evaluation, risk management, and risk communication.
\end{abstract}

Keywords Ambiguity · Complexity · Coping strategies · Integrated urban risk management $\cdot$ Risk

Ortwin Renn

ortwin.renn@iass-potsdam.de

1 Institute for Advanced Sustainability Studies (IASS), 14467 Potsdam, Germany

2 Environmental Policy Institute, Memorial University of Newfoundland, Grenfell Campus, Corner Brook, NL A2H 5G4, Canada assessment · Risk evaluation · Risk

governance · Uncertainty

\section{Introduction}

The concept of risk governance includes both the institutional structure and the policy process that guide and restrain the collective activities of a group, society, or international community to regulate, reduce, or control risk problems (Renn and Klinke 2014; Klinke and Renn 2018). Contemporary handling of collectively relevant risk problems has been shifted away from traditional state-centric approaches with hierarchically organized governmental agencies to separately constituted public bodies with overlapping jurisdictions and vertical governance structures that link the community level to regional, national, and international levels, which do not match the traditional hierarchical order but constitute polyarchical structures (Hooghe and Marks 2003; Skelcher 2005; Okada 2018). This implicates an increasingly multilayered and diversified sociopolitical landscape in which a multitude of actors, each individual with their own perceptions and evaluations, draw on a diversity of knowledge and evidence claims, value commitments, and political interests in order to influence processes of risk analysis, decision making, and risk management (Jasanoff 2004). Institutional diversity can offer considerable advantages:

(1) Risk problems that affect different urban constituencies at the same time can be managed in accordance with each unique set of spatial conditions specificity;

(2) An inherent degree of overlap and redundancy makes nonhierarchical adaptive and integrative risk 
governance systems more resilient and therefore less vulnerable (Renn and Klinke 2014);

(3) The larger number of actors facilitates experimentation and learning (Renn 2008);

(4) This approach includes the experiences from direct community-building efforts and links the various agency levels into an integrated structure of governance (Higo et al. 2017; Okada 2018);

(5) This approach is sensitive to different cultural contexts and community situations (Renn and Schweizer 2009).

Disadvantages refer to the possible commodification of risk; the fragmentation of the risk governance process; costly collective risk decision making; and the potential loss of democratic accountability (Charnley 2000). Understanding the dynamics, structures, and functionality of risk governance processes requires a general and comprehensive conceptualization of procedural mechanisms and structural configurations. The classic model of risk analysis consisting of three components-risk assessment, management, and communication-proves to be too narrowly focused on regulatory bodies to be capable of covering the variety of actors and processes involved in governing risk. Therefore, it is necessary to enrich the classic model by adding two additional steps called risk evaluation and pre-estimation (IRGC 2005). Furthermore, risk governance incorporates expert, stakeholder, and public involvement as a core feature in the stage of communication and deliberation.

Based on previous work by Klinke and Renn on risk governance and risk evaluation (Renn 2008, 2015, 2017; Renn and Klinke 2013, 2016a; Klinke and Renn 2018), we will outline three major characteristics of risk that pose specific challenges for risk governance and entail particular forms of involvement of actor groups. Subsequently, we will then address major functions of the risk governance process: pre-estimation, interdisciplinary risk estimation, which includes scientific risk assessment and concern assessment, risk characterization and risk evaluation, as well as risk management including decision making and implementation after which we will relate these variables to urban risks. Furthermore, we will explicate the design of an effective and fair institutional arrangement that includes four different forms of public and stakeholder involvement in order to cope with the challenges raised by complexity, uncertainty, and ambiguity. Finally, the article concludes with some general lessons for urban risk governance.

\section{Three Characteristics of Risk Knowledge}

Adaptive and integrative governance on risk is intended to address challenges raised by three risk characteristics that result from a lack of knowledge and/or competing knowledge claims about the risk problem. The three characteristics are complexity, scientific uncertainty, and sociopolitical ambiguity (Klinke and Renn 2010; Renn et al. 2011).

\subsection{Complexity in Identifying Causality and Functional Relationships}

Complexity refers to the difficulty of identifying and quantifying causal links between a multitude of potential candidates and specific adverse effects (Waldrop 1992; Underdal 2009). A crucial aspect in this respect concerns the applicability of probabilistic risk assessment techniques. If the chain of events between a cause and an effect follows a linear relationship, for example, in car accidents or in a building collapse due to a hurricane, simple statistical models are sufficient to calculate the probabilities of harm. Such simple relationships may still be associated with high uncertainty, for example, if only limited data are available or the effect is stochastic by its own nature-for instance an earthquake. Sophisticated models of probabilistic inferences are required if the relationship between cause and effects becomes more complex (Renn and Walker 2008a). The nature of this difficulty may be traced back to interactive effects among these candidates, synergisms and antagonisms, positive and negative feedback loops, long delay periods between cause and effect, interindividual variation, intervening variables, and others. Precisely these complexities make sophisticated scientific investigations necessary, since the cause-effect relationship is neither obvious nor directly observable. Complexity requires sensitivity to nonlinear transitions as well as to scale on different levels. Examples of highly complex risk include nested chemical facilities that may threaten nearby settlements, synergistic effects of potentially toxic substances in urban air, failure risk of large interconnected infrastructures such as water and electricity grids, and risks of critical loads placed on sensitive ecosystems within human settlements.

\subsection{Scientific Uncertainty: From Variability to Indeterminancy}

Scientific uncertainty may result from unresolved complexity, in particular if the cause-effect models show large confidence intervals (Marti et al. 2010). It relates to the limitedness or even absence of scientific proof for a causal 
or functional relationship that makes it difficult to assess exactly the probability and possible outcomes of undesired effects (Aven and Renn 2009; Filar and Haurie 2010). It is essential to acknowledge in the context of risk assessment that human knowledge is always incomplete and selective, and thus is contingent upon uncertain assumptions, assertions, and predictions (Functowicz and Ravetz 1992; Laudan 1996; Renn 2008). It is obvious that modeled probability distributions within a numerical relational system can only represent an approximation of the empirical relational system that helps elucidate and predict uncertain events. It therefore seems prudent to include additional aspects of uncertainty (van Asselt 2000). Examples of high uncertainty include many natural hazard-induced disasters, such as earthquakes, possible health effects of airborne pollutants below the threshold of statistical significance, acts of violence such as terrorism and sabotage, and longterm effects of high social mobility on personal wellbeing and social cohesion (Okada 2018).

\subsection{Sociopolitical Ambiguity: Interpretation and Acceptability}

While more and better data and information may reduce scientific uncertainty, more knowledge does not necessarily reduce ambiguity. Ambiguity thus indicates a situation of ambivalence in which different and sometimes divergent streams of thinking and interpretation about the same risk phenomena and their circumstances are apparent (Feldman 1989; Zahariadis 2003; Renn and Klinke 2014; Renn and Klinke 2016b). We must distinguish between interpretative and normative ambiguity because both relate to divergent or contested perspectives on the justification, severity, or wider "meanings" associated with a given threat.

Interpretative ambiguity denotes the variability of legitimate interpretations based on identical observations or data assessment results, for example, an adverse or nonadverse effect. Variability of interpretation, however, is not restricted to expert dissent. Laypeople's perception of risk often differs from expert judgments because it is related to qualitative risk characteristics such as familiarity, personal or institutional control, assignment of blame, and others. Moreover, in contemporary pluralist societies diversity of risk perspectives within and between social groups is generally fostered by divergent value preferences, variations in interests, and very few, if any, universally applicable moral principles. Ambiguity becomes all the more prominent, if risk problems are also complex and uncertain.

That leads to normative ambiguity, which alludes to different concepts of what can be regarded as tolerable, and is encountered in particular in ethics, quality of life parameters, and the distribution of risks and benefits. A condition of ambiguity emerges when the problem lies in agreeing on the appropriate values, priorities, assumptions, or boundaries to be applied to the definition of possible outcomes. Dealing with ambiguities requires governance approaches that emphasize mutual learning across different academic and practical communities as well as promote the co-creation of joint knowledge and practical applications (Rose 2018). Examples for high interpretative ambiguity include exposure to low dose radiation ionizing and nonionizing, low concentrations of genotoxic substances, food supplements and, in the social domain, the gentrification of urban quarters or the loss of social cohesion in a disasterprone community. Normative ambiguities can be associated, for example, with passive smoking, restricted mobility regimes in highly congested cities such as city maut [congestion tax assessed on vehicles in central cities (Konishi and Mun 2010)] zoning laws for hazard-prone areas, or busing of schoolchildren from different social classes.

Most risks are characterized by a mixture of complexity, uncertainty, and ambiguity. Passive smoking may be a good example of low complexity and uncertainty, but high ambiguity, in particular with respect to acceptability. Nuclear energy may be a good candidate for high complexity and high ambiguity, but relatively little uncertainty. The risks of a melt-down or other accidents are well explored and the confidence intervals in the probability functions are well defined. The use of information technology in smart urban environments could be cited as an example for high complexity, uncertainty, and ambiguity. These technologies provide a lot of sophisticated services, are interconnected, will lead to many, unexpected consequences, and are controversial in the public debate.

\section{Adaptive and Integrative Capacity of Risk Governance}

The ability of risk governance institutions to cope with complex, uncertain, and ambiguous consequences and implications has become a central concern to scientists and practitioners alike. Adaptive and integrative governance on risk can broadly be understood as the ability of politics and society to collectively design and implement a systematic approach to organizational and policy learning in institutional settings that are conducive to resolving complexity, uncertainty, and ambiguity in risk arenas. ${ }^{1}$

Risk governance includes a dynamic governance process of continuous and gradual learning and adjustment.

\footnotetext{
1 To the definition and understanding of adaptive capacity, see, for example, Armitage et al. (2007), Berkhout et al. (2006), and Webster (2009).
} 


\section{Governance Institution}

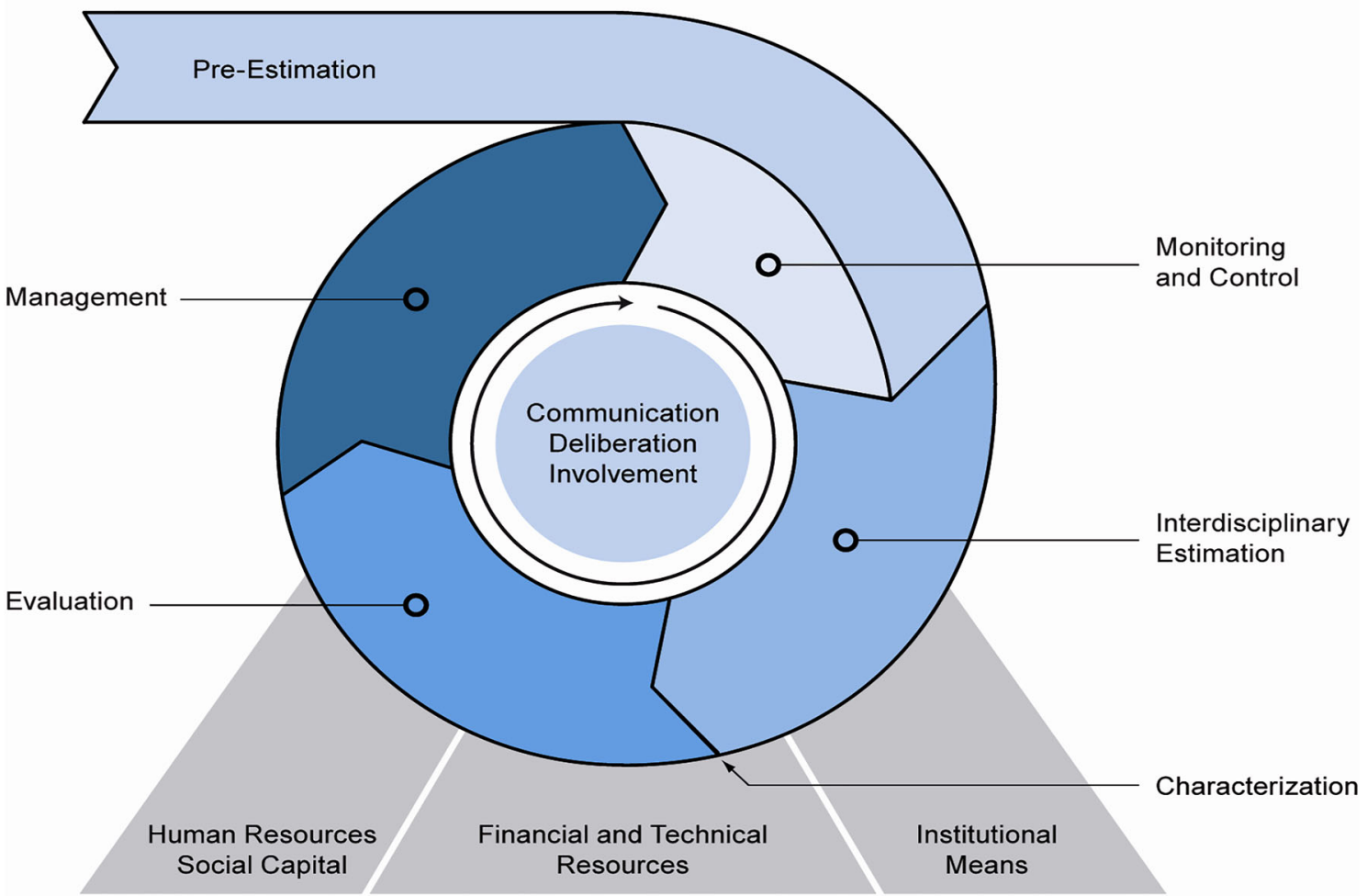

Fig. 1 Adaptive and integrative risk governance model adapted from Klinke and Renn (2012) [The adaptive and integrative risk governance model is based on a modification and refinement of the IRGC framework (IRGC 2005)]

Adaptive and integrative capacity in risk governance processes encompasses a broad array of structural and procedural mechanisms by which politics and society can handle collectively relevant risk problems. In practical terms, adaptive and integrative capacity is the ability to design and incorporate the necessary steps in a risk governance process that allow risk managers to reduce, mitigate, or control, in an effective, efficient, and fair manner, the occurrence of harmful outcomes resulting from collectively relevant risk problems (Brooks and Adger 2005; Renn 2015).

Adaptive and integrative governance on risk and uncertainty requires a set of resources available for accomplishing the tasks associated with the prudent handling of complexity, uncertainty, and ambiguity. In 2005, the International Risk Governance Council suggested a process model of risk governance based on the work of several scholars (IRGC 2005; Renn 2008; Renn and Walker 2008a; Klinke and Renn 2012). This framework structures the risk governance process in four phases: preassessment, appraisal, characterization/evaluation, and risk management. Communication and stakeholder involvement were conceptualized as constant companions to all four phases of the risk governance cycle. Based on this framework, and informed by many comments on the original framework, for example the edited volume by Renn and Walker (2008b), Klinke and Renn modified the original IRGC proposal. The new framework suggested in this article consists of the steps: pre-estimation, interdisciplinary risk estimation, risk characterization, risk evaluation, and risk management. This is all related to the ability and capacity of risk governance institutions to use resources effectively (see Fig. 1).

Appropriate resources include institutional and financial means, as well as social capital (for example, strong institutional mechanisms and configurations), transparent decision making, allocation of decision-making authority, formal and informal networks that promote collective risk handling, education, technical resources (for example, databases, computer soft- and hardware, and so on), and human resources (for instance, skills, knowledge, expertise, epistemic communities, among others). Hence the adequate involvement of experts, stakeholders, and the public in the risk governance process is a crucial dimension to produce and convey adaptive and integrative capacity in risk governance institutions (Pelling et al. 2008). The characterization of risk includes the integration of the interdisciplinary estimation (assessment) with the context description in which the risk is embedded (resources, governance structures, capabilities). 


\section{Pre-estimation: A Systematic Review}

A systematic review of the stages in pre-estimation would start with "screening" as an exploration of a large array of actions and problems looking for those components with a specific risk-related feature. It is important to explore what major political and societal actors (such as governments, companies, epistemic communities such as the community of risk analysis specialists, professional toxicology or epidemiology associations, or communities for disaster management, nongovernmental organizations, and the general public) identify as risks and what types of problems they label as problems associated with risk and uncertainty. This is called "framing" and this process specifies how society and politics rely on schemes of selection and interpretation to understand and respond to those phenomena in order to identify what is socially constructed as relevant risk topics (Nelson et al. 1997; Kahneman and Tversky 2000; Reese et al. 2003).

Interpretations of risk experience depend on frames of reference (Daft and Weick 1984). The process of framing corresponds with a multiactor and multiobjective governance structure, since governmental authorities, national, supranational, and international agencies, risk and opportunity producers (for example, industry), those affected by risks and opportunities (for example, consumer organizations), environmental groups, and interested bystanders (for example the media or an intellectual elite) are all involved and are often in conflict with each other about the appropriate frame within which to conceptualize the problem. What counts as risk may vary among these actor groups. Whether an overlapping consensus evolves about what requires consideration as a relevant risk depends on the legitimacy of the selection rule. It is particularly important to understand how risks are framed in a community that is exposed to the risk (Renn and Klinke 2013, 2014). Often communities are very familiar with natural hazards and are skeptical about the way that outside experts frame and assess the risks. In other instances, communities may be highly concerned about a risk exposure-for example a water or air pollutant - that seems to be relatively benign to many toxicologists or other experts.

How does this phase of pre-estimation relate to risks in urban environments? Architects, builders, urban planners, industrial contractors, real estate agents, and last but not least the affected population all have different expectations and concerns that should be addressed before a risk management plan is released (Renn and Klinke 2014). The idea is to collect these different frames and make them an integral part of the urban renewal or development plan. Risk and hazard management should not be isolated from other community-based planning processes. The best instrument for implementing such an input is by interviewing key people in the process of developing the plan and to conduct a survey among residents about their preferences and concerns (Renn 2008). In addition, it might be advisable to establish a round table in which different concepts are discussed and a consensus reached about the main goals and required steps to reach them.

\section{Interdisciplinary Risk Estimation}

Interdisciplinary risk estimation requires the cooperation of all disciplines that are necessary to generate a common understanding of all the risk consequences-physical, monetary, social, and cultural. The estimation process comprises two stages (IRGC 2005; Renn and Walker 2008a):

(1) Risk assessment: experts of natural and technical sciences produce the best estimate of the physical harm that a risk source may induce; such harm could be the collapse of buildings, discontinuation of central services to residents such as water, electricity, or information, breakdown of traffic, and inadequacy of infrastructural support; and

(2) Concern assessment: experts of social sciences, including economics, identify and analyze the issues that individuals or society as a whole link to a certain risk. Not only dysfunctional social services and risks of economic activities but also risks based on perceptions of crime or insecurity belong to this portfolio. To identify and explore these risks, the repertoire of the social sciences, such as survey methods, focus groups, econometric analysis, macroeconomic modeling, or structured hearings with stakeholders may be used.

In reference to urban risks, the phase of interdisciplinary estimation includes two consecutive steps: First, it is mandatory to assess each risk that one faces in the planning, governing, and regulating of urban districts. These risks can refer to exposure to natural hazards, technical failures, infrastructure failure or inefficiency, planning mistakes, inadequate building codes, and inadequate consideration of social needs and preferences (Klinke and Renn 2014). These risks are very different in nature and require specific techniques to address them. But they all have in common that they include a hazard assessment (what is the potential harm?), an exposure assessment (who and what might be affected?), a vulnerability analysis (what harm or damage can be expected for whom and to what degree?), and finally a quantitative or at least qualitative risk estimate, which combines the hazard, exposure, and vulnerability assessments into an overall risk profile. 
Once these profiles have been constructed, it is very important to understand the connections between these risks. Some minor risk in one part can augment or amplify risks in another area (Burns et al. 1993). Formally such an integration can be performed by using influence diagrams or Petri nets.

The second step in risk estimation is the inclusion of the concerns and expectations held by those involved in managing or governing urban risks. The main idea is to collect the necessary knowledge possessed by stakeholders and affected citizens about their preferences in terms of risk reduction and risk handling. This step is often forgotten but is essential in order to match physical risk assessments with human perception (van Asselt and Renn 2011). Among the instruments to perform such a concern assessment one can suggest group Delphi processes or hearings (Renn 2008).

\section{Risk Evaluation and the Traffic Light Model}

A heavily disputed task in the risk governance process relates to the procedure employed to classify a given risk and justify an evaluation about its societal acceptability or tolerability (see Fig. 2). In many approaches, risks are ranked and prioritized based on a combination of probability (how likely is it that the risk will occur and impact; what are the consequences, if the risk does occur). In the so-called traffic light model, risks are located in the diagram of probability versus expected consequences and three areas are identified: green, amber, and red (Renn 2008):

A risk falls into the green area if the occurrence is highly unlikely and the impact is negligible. No further formal intervention is necessary. A risk is seen as tolerable when serious impacts might occur occasionally (amber area). The benefits are worth the risk, but risk reduction measures are necessary. Finally, a risk is viewed as intolerable when the occurrence of catastrophic impacts is most likely (red area). Possible negative consequences of the risk are so catastrophic that in spite of potential benefits it cannot be tolerated.

To draw the lines between "acceptable" (green area), "tolerable" (amber area), and "intolerable" (red area) is one of the most controversial tasks in the risk governance process. The UK Health and Safety Executive developed a procedure for chemical risks based on risk-risk comparisons (Löfstedt 1997). Some Swiss cantons, such as Basle County, experimented with round tables as a means to reach consensus on drawing the two demarcation lines, whereby participants in the round table represented industry, administrators, county officials, environmentalists, and neighborhood groups. The round table was facilitated by a professional mediator whose task was to reach a consensus between the various groups. Such a consensus was difficult to achieve, but in the end all the parties agreed with a solution by which the demarcation lines were only determined for a limited time with the clear understanding that the standards would be tightened if more risk reduction

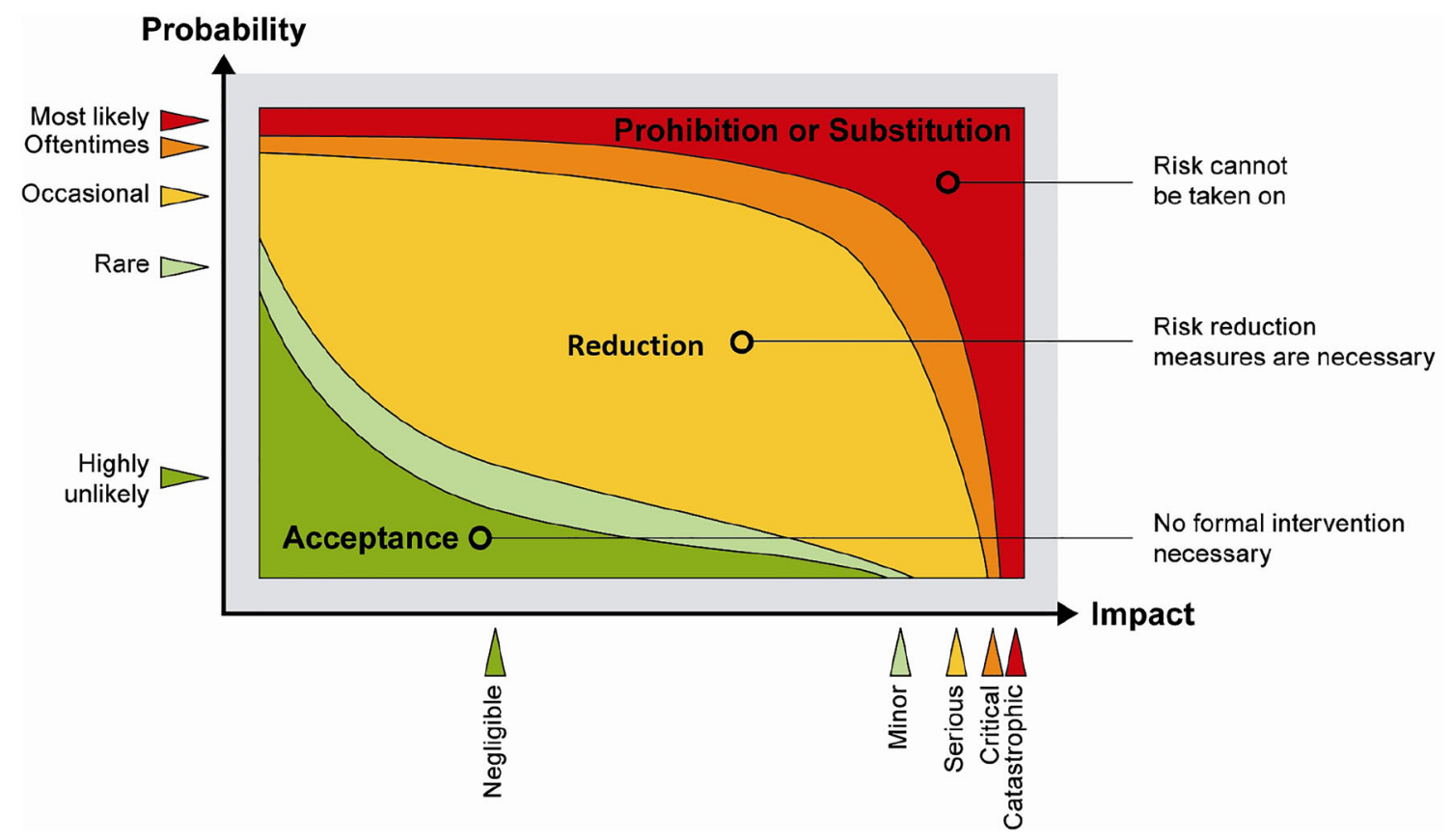

Fig. 2 Risk areas: intolerable red, tolerable amber, acceptable green Source: Renn (2008) 
measures became available and were further developed (Keller 2000).

Irrespective of the selected means to support this task, the judgment on acceptability or tolerability is contingent on making use of a variety of different knowledge sources. One needs to include the data and insights resulting from the risk assessment activity, and additional data from the concern assessment.

In the context of urban risks, it is important to have different management plans or options available and to compare these options from both sides: the opportunities including potential revenues, and the risks including financial costs and liabilities. It is recommended to use either multicriteria or multiattribute decision-analytic models to identify potential conflicts between objectives and criteria and to assign tradeoffs between these conflicting objectives (Keeney 1992; Keeney and McDaniels 2002). Stakeholders and representatives of the public should be asked to assist in determining relative weights among options, thus reflecting plural value input (Arvai et al. 2001; Hagendijk and Irwin 2006). It may also be advisable to have the active members of a community exposed to a certain risk to develop their own criteria for evaluating the risks and potential responses to deal with them (Okada et al. 2013a).

\section{Risk Management in a Risk Tolerance Setting}

Risk management starts by reviewing all relevant data and information generated in the previous steps of interdisciplinary risk estimation, characterization, and risk evaluation. The systematic analysis of risk management options focuses on still tolerable risks (amber area) and those where tolerability is disputed (light green and orange transition zones). The other cases (green and red areas) are fairly easy to deal with. Intolerable risks demand prevention and prohibition strategies as a means of replacing the hazardous activity with another activity leading to identical or similar benefits. The management of acceptable risks is left to private actors, the public, and economy. They may initiate additional and voluntary risk reduction measures or to seek insurance to cover possible but rather minor or negligible losses. If risks are classified as tolerable, or if there is a dispute as to whether they are in the transition zones of tolerability, public risk management needs to design and implement actions that make these risks either acceptable or at least tolerable by introducing reduction strategies. Based on the distinction in complexity, scientific uncertainty, and sociopolitical ambiguity, it is possible to design general strategies for risk management that can be applied to four distinct categories of risk problems, thus simplifying the process of risk management (Renn 2008; Renn and Klinke 2014).

The first category refers to linear risk problems: they are characterized as having low scores on the dimensions of complexity, uncertainty, and ambiguity. They can be addressed by linear risk management because they are normally easy to assess and quantify. Routine risk handling within risk assessment agencies and regulatory institutions is appropriate for this category. Since the risk problems are well known, sufficient knowledge of key parameters is available, and there are no major controversies about causes and effects or conflicting values. The management includes risk-benefit analysis, risk-risk comparisons, or other instruments that balance the pros and cons of the problem.

If risks are ranked high on complexity but rather low on uncertainty, that is, the complexity can be widely resolved by adequate scientific models, and high ambiguity, they require a systematic involvement and deliberation of experts representing the relevant epistemic communities to produce the most accurate estimate of the complex relationships. It does not make much sense to integrate public concerns, perceptions, or any other social aspects for resolving complexity unless specific knowledge from the concern assessment helps to untangle complexity. Complex risk problems therefore demand risk-informed management that can be offered by scientists and experts who apply methods of expanded risk assessment, determine quantitative safety goals, consistently use cost-effectiveness methods, and monitor and evaluate outcomes.

Risk problems that are characterized by high uncertainty but low ambiguity require precaution-based management. Since sufficient scientific certainty is currently either not available or unattainable, expanded knowledge acquisition may help to reduce uncertainty and move the risk problem back to the first stage of handling complexity. If, however, uncertainty cannot be reduced by additional knowledge, risk management should foster and enhance precautionary and resilience-building strategies and decrease vulnerabilities in order to avoid irreversible effects. Appropriate instruments include containment, diversification, monitoring, and substitution. Because the focal point here is to find the adequate and fair balance between being overcautious versus being not cautious enough, a reflective processing involving stakeholders is necessary to ponder concerns, economic budgeting, and social evaluations.

Finally, if risk problems are ranked high on ambiguity regardless of whether they are low or high on uncertainty, discourse-based management is required, which demands participative processing. This includes the need to involve major stakeholders as well as the affected public. The goals of risk management are to produce a collective understanding among all stakeholders and concerned public on 
interpretative ambiguity or to find legitimate procedures that justify collectively binding decisions on acceptability and tolerability. It is important that a consensus or a compromise is achieved between those who believe that the risk is worth taking, perhaps because of self-interest, and those who believe that the pending consequences do not justify the potential benefits of the risky activity or technology.

Applying these risk management regimes to urban risks, one can envisage the following idealized risk management process: At the beginning of the risk management process, it is required to design and assess different risk reduction measures. Such a risk profile will show potential opportunities but also deficits in terms of risks or social concerns. This is now the phase in which concrete risk reduction options are generated, discussed, and selected. Depending on the degree of complexity, uncertainty, and ambiguity, one should choose risk reduction options that relate to best available technical knowledge (high complexity), emphasize reversibility and robustness (high uncertainty), and include participatory instruments in case of high ambiguity (Renn and Klinke 2014). If the risk reduction program is controversial or includes value conflicts, instruments such as citizen panels or citizen advisory groups would be highly recommended (Rowe and Frewer 2000). In many communities in Japan the model of open campus systems to co-develop and deliberate risk reduction options have proven to be rather effective (Okada et al. 2013b).

\section{Risk Communication at an Intensive Level}

All four phases need to be accompanied by intensive risk communication efforts. Communication should not be limited to sharing information but includes the effort to create both a common understanding of the problems and challenges as well as a joint agreement on the most acceptable risk reduction solutions. This concept of communication requires a transdisciplinary approach to problem solving that includes the strong participation of all relevant stakeholders in the creation of knowledge and risk reduction options (Hirsch-Hadorn et al. 2008). Communication in this understanding should start already during the pre-estimation phase. It should convey the basic concepts and what these concepts entail in terms of opportunities and risks. Feedback channels can be arranged on the Internet as a means to scan the responses by stakeholders and affected citizens. During the risk estimation phase the communication process should emphasize the process by which the research and planning team conducts the risk assessments. The main goal here is to promote trust in the risk handling authorities (Löfstedt 2005).
It might be helpful to ask stakeholders and citizens for additional knowledge that the public officials may not have. More input from the public is encouraged during the evaluation phase. First of all, the process of how tradeoffs are assigned and justified needs to be made transparent to all stakeholders as well as the general public. Furthermore, depending on the degree of ambiguity, it might be useful to have procedures in place that systematically collect feedback and concerns with respect to the planned urban risk management measures. During the management phase, it is essential to familiarize all affected persons with the chosen or deliberated risk reduction measures, in particular those that rely on cooperation of the affected public such as evacuation or sheltering plans. Instruments for making risk reduction plans known to the public are open meetings, brochures, websites, TV shows, and other popular forms of information transfer (Earle and Cvetkovich 1994).

\section{Inclusive Governance: The Need for an Effective Inclusion of Experts, Stakeholders, and the Public}

The effectiveness and legitimacy of the risk governance process depend on the capability of the management agencies to resolve complexity, characterize uncertainty, and handle ambiguity by means of communication and deliberation. In the following, a particular procedural mechanism of communication and deliberation to address each of the specific challenges raised by complexity, scientific uncertainty, and sociopolitical ambiguity is introduced.

\subsection{Instrumental Processing Involving Governmental Actors}

Dealing with linear risk issues, which are associated with low scores of complexity, scientific uncertainty, and sociopolitical ambiguity, requires hardly any changes to conventional public policy making. The data and information of such linear routine risk problems are provided by statistical analysis. Law or statutory requirements determine the general and specific objectives, and the role of public policy is to ensure that all necessary measures of safety and control are implemented and enforced. The aim is to find the most cost-effective method for a desired regulation level. If necessary, stakeholders may be included in the deliberations as they have information and know-how that may provide useful hints for being more efficient. 


\subsection{Epistemic Processing Involving Experts and Stakeholders}

Resolving complex risk problems requires dialogue and deliberation among experts and representative of stakeholder groups with special knowledge and experience. Involving members of various epistemic communities that have demonstrated expertise and competence is the most promising step in producing more reliable and valid judgments about the complex nature of a given risk. Epistemic discourse is the instrument for discussing the conclusiveness and validity of cause-effect chains relying on available probative facts, uncertain knowledge, and experience that can be tested for empirical traceability and consistency. The objective of such a deliberation is to find the most cogent description and explanation of the phenomenological complexity in question as well as a clarification of dissenting views, for example by addressing the question of which environmental and socioeconomic impacts are to be expected by specific community action plans. Deliberation among experts might generate a profile of the complexity of the given risk issue on selected intersubjectively chosen criteria. The deliberation may also reveal that there is more uncertainty and ambiguity hidden in the case than the initial appraisers had anticipated. It is advisable to include natural as well as social scientists in the epistemic discourse so that potential problems with risk perception can be anticipated. If this practice was followed, controversies would occur less as a surprise than is now often the case.

\subsection{Reflective Processing Involving Stakeholders}

Characterizing and evaluating risks as well as developing and selecting appropriate management options for risk reduction and control in situations of high uncertainty pose particular challenges. How can risk managers characterize and evaluate the severity of a risk problem when the potential damage and its probability are unknown or highly uncertain? Scientific input is therefore only the first step in a series of steps during a more sophisticated evaluation process. It is crucial to compile the relevant data and information about the different types of uncertainties to inform the process of risk characterization. The outcome of the risk characterization provides the foundation for a broader deliberative arena in which not only policymakers and scientists are involved. Directly affected stakeholders and public interest groups, including representatives of the affected public in urban areas, ought to be involved in order to discuss and ponder the "right" balances and trade-offs between potential over- and under-protection. This reflective involvement of stakeholders and interest groups pursues the purpose of finding a consensus on the extra margin of safety that potential victims would be willing to tolerate and potential beneficiaries of the risk would be willing to invest in order to avoid potentially critical and catastrophic consequences. The reflective involvement of policymakers, scientists, stakeholders, and public interest groups can be accomplished by a spectrum of different forms such as negotiated rule-making, mediation, round table or open forum, and advisory committee (Rowe and Frewer 2000; Beierle and Cayford 2002; Stoll-Kleemann and Welp 2006).

\subsection{Participative Processing Involving the Public}

If risk problems are associated with high ambiguity, it is not enough to demonstrate that risk regulation addresses the issues of public concerns. In these cases, the process of evaluation needs to be open to public input and new forms of deliberation. This starts with revisiting the question of proper framing. Is the issue really a risk problem or is it an issue of lifestyle or future vision? Often the benefits are contested as well as the risks. The debate about smart cities may illustrate the point that observers may be concerned not only about technical risks of network failures or privacy issues being violated by information transfer but also about the acceptability of a desired goal that reduces choices for individuals by means of a paternalistic design of choice situations (Thaler and Sunstein 2009; Kahneman 2011). The controversy is often much broader than dealing with risks only. The aim here is to find an overlapping consensus on the dimensions of ambiguity that need to be addressed in comparing risks and benefits, and balancing pros and cons. High ambiguity would require the most inclusive strategy for involvement because not only directly affected groups but also those indirectly affected should have an opportunity to contribute to this debate. Resolving ambiguities in risk debates necessitates a participatory involvement of the public to openly discuss competing arguments, beliefs, and values. The set of possible forms to involve the public includes citizen panels or juries, citizen forums, consensus conferences, public advisory committees, and similar approaches (Rowe and Frewer 2000; Beierle and Cayford 2002; Hagendijk and Irwin 2006; Abels 2007).

\section{Conclusions}

This article attempted to expand the framework on risk governance in the direction of more adaptability and institutional capacity to include various actors and knowledge camps including community leaders and affected citizen groups when addressing and regulating risks of urban planning. At the core of this article was the idea of adaptive and integrative risk governance for urban risk. The goal has been to illustrate how the different components of preestimation, interdisciplinary risk estimation, 
risk characterization, risk evaluation, risk management, as well as communication and involvement interact with each other and to demonstrate how the various combinations of complexity, uncertainty, and ambiguity can be addressed by different risk management strategies.

This generic risk governance model is particularly suited to deal with community and urban risks. The risks that people are facing in urban environments are financial risks, physical risks (natural hazards), technological risks (building structures, infrastructure, hazardous facilities), and social risks (violence, social dissatisfaction). These types of risks are all interconnected and need to be considered when effective risk management plans are designed and implemented (Renn and Klinke 2014).

The analytic distinction of risk characteristics-complexity, uncertainty, and ambiguity—helps to facilitate an integrated approach to risk governance and urban risk management. Whereas the analysis of simple and-to some degree-complex problems is better served by relying on the physical understanding of risks, uncertain and ambiguous problems demand the integration of social constructions and mental models for both understanding and managing these problems since the risk conditions in urban areas affect the livelihood of people with all their beliefs, expectations, and emotions. The distinction of risks according to risk characteristics not only highlights deficits in our knowledge concerning adequate risk handling in urban contexts, but also points the way forward for the selection of management options. Thus, the risk governance framework attributes an important function to public and stakeholder participation, as well as risk communication, in the risk governance process. The framework suggests efficient and adequate public or stakeholder participation procedures. The concerns of stakeholders and/or the public are integrated in the risk appraisal phase via concern assessment. Furthermore, stakeholder and public participations are an established part of risk management. The optimum participation method depends on the characteristics of the risk issue. In this respect, all aspects that matter to people in urban risk governance are taking into account in the various discourses through the images that the participants bring into the discussions. The need for finding an agreement on the respective time and space boundaries, underlines the necessity to understand and comprehend the various concepts and images that people associate with quality of life in urban environments.

Open Access This article is distributed under the terms of the Creative Commons Attribution 4.0 International License (http://crea tivecommons.org/licenses/by/4.0/), which permits unrestricted use, distribution, and reproduction in any medium, provided you give appropriate credit to the original author(s) and the source, provide a link to the Creative Commons license, and indicate if changes were made.

\section{References}

Abels, G. 2007. Citizen involvement in public policymaking: Does it improve democratic legitimacy and accountability? The case of pTA. Interdisciplinary Information Science 13(1): 103-116.

Armitage, D., F. Berkes, and N. Doubleday. 2007. Adaptive comanagement: Collaboration, learning and multilevel governance. Vancouver: University of British Columbia Press.

Arvai, J.L., R. Gregory, and T. McDaniels. 2001. Testing a structured decision approach: Value-focused thinking for deliberative risk communication. Risk Analysis 21(6): 1065-1076.

Asselt, M.B.A. van. 2000. Perspectives on uncertainty and risk: The PRIMA approach to decision support. Dordrecht and Boston: Kluwer Academic.

Asselt, M.B.A. van, and O. Renn. 2011. Risk governance. Risk Research 14(4): 431-449.

Aven, T., and O. Renn. 2009. The role of quantitative risk assessments for characterizing risk and uncertainty and delineating appropriate risk management options, with special emphasis on terrorism. Risk Analysis 29(4): 587-600.

Beierle, T.C., and J. Cayford. 2002. Democracy in practice: Public participation in environmental decisions. Washington, DC: Resources for the Future.

Berkhout, F., J. Hertin, and D.M. Gann. 2006. Learning to adapt: Organisational adaptation to climate change impacts. Climate Change 78(1): 135-156.

Brooks, M., and W.N. Adger. 2005. Assessing and enhancing adaptive capacity. In Adaptation policy frameworks for climate change: Developing strategies, policies and measures, ed. K. Chopra, R. Leemans, P. Kumar, and H. Simons, 165-181. Cambridge: Cambridge University Press.

Burns, W.J., P. Slovic, R.E. Kasperson, J.X. Kasperson, O. Renn, and S. Emani. 1993. Incorporating structural models into research on the social amplification of risk: Implications for theory construction and decision making. Risk Analysis 13(6): 611-623.

Charnley, G. 2000. Democratic science: Enhancing the role of science in stakeholder-based risk management decision-making. Report of health risk strategies. Washington, DC: Health Risk Strategies.

Daft, R.L., and K.E. Weick. 1984. Toward a model of organizations as interpretation systems. Academy of Management Review 92(2): 284-295.

Earle, T.C., and G. Cvetkovich. 1994. Risk communication: The social construction of meaning and trust. In Future risks and risk management, ed. B. Brehmer, and N.E. Sahlin, 243-267. Amsterdam: Kluwer.

Feldman, M.S. 1989. Order without design: Information production and policy making. Stanford, CA: Stanford University Press.

Filar, J.A., and A. Haurie (eds.). 2010. Uncertainty and environmental decision making. New York: Springer.

Functowicz, S.O., and J.R. Ravetz. 1992. Three types of risk assessment and the emergence of post-normal science. In Social theories of risk, ed. S. Krimsky, and D. Golding, 251-273. Westport and London: Praeger.

Hagendijk, R., and A. Irwin. 2006. Public deliberation and governance: Engaging with science and technology in contemporary Europe. Minerva 44(2): 167-184.

Higo, E., N. Okada, K.W. Hipel, and L. Fang. 2017. Cooperative survival principles for underground flooding: Vitae system based multi-agent simulation. Expert Systems with Applications 83: 379-395.

Hirsch-Hadorn, G., S. Biber-Klemm, W. Grossenbacher-Mansuy, H. Hoffmann-Riem, D. Joye, C. Pohl, U. Wiesmann, and E. Zemp. 2008. The emergence of transdisciplinarity as a form of research. In Handbook of transdisciplinary research, ed. G.H. Hadorn, H. 
Hoffmann-Riem, S. Biber-Klemm, W. Grossenbacher-Mansuy, D. Joye, C. Pohl, U. Wiesmann, and E. Zemp, 19-42. Berlin and Heidelberg: Springer.

Hooghe, L., and G. Marks. 2003. Unraveling the central state, but how? Types of multi-level governance. American Political Science Review 97(2): 233-243.

IRGC (International Risk Governance Council). 2005. Risk governance: Towards an integrative approach. White paper No.1. Geneva: IRGC.

Jasanoff, S. 2004. Ordering knowledge, ordering society. In States of knowledge: The co-production of science and social order, ed. S. Jasanoff, 13-45. London: Routledge.

Kahneman, D. 2011. Thinking, fast and slow. New York: Penguin.

Kahneman, D., and A. Tversky (eds.). 2000. Choices, values, and frames. Cambridge: Cambridge University Press.

Keeney, R. 1992. Value-focused thinking: A path to creative decision making. Cambridge: Harvard University Press.

Keeney, R., and T. McDaniels. 2002. A framework to guide thinking and analysis regarding climate change policies. Risk Analysis 21(6): 989-1000.

Keller, D. 2000. The Risk Commission assesses the acceptability of risks since 10 years (Seit 10 Jahren beurteilt die RISKO die Tragbarkeit von Risiken). RISKO: Mitteilungen für Kommission für Risikobewertung des Kantons Basel-Stadt. Bulletin 3: 1. http://www.aue.bs.ch/dam/jcr:71e2e305-fcd9-490a-9952-

488612e857c1/fu_5_3_bulletin3_00.pdf. Accessed 11 Nov 2018 (in German)

Klinke, A., and O. Renn. 2010. Risk governance: Contemporary and future challenges. In Regulating chemical risks: European and global challenges, ed. J. Erisksson, M. Gilek, and Ch. Ruden, 9-28. Heidelberg: Springer.

Klinke, A., and O. Renn. 2012. Adaptive and integrative governance on risk and uncertainty. Journal of Risk Research 15(3): 273-292.

Klinke, A., and O. Renn. 2018. Distributed responsibility in risk governance. In Sustainable risk management, ed. P.A. Wilderer; O. Renn, M. Grambow, M. Molls, and K. Mainzer, 19-32. Heidelberg: Springer.

Konishi, H., and S. Mun. 2010. Carpooling and congestion pricing: HOV and HOT lanes. Regional Science and Urban Economics 40(4): 173-186.

Laudan, L. 1996. The pseudo-science of science? The demise of the demarcation problem. In Beyond positivism and relativism: Theory, method and evidence, ed. L. Laudan, 166-192. Boulder: Westview Press.

Löfstedt, R.E. 1997. Risk evaluation in the United Kingdom: Legal requirements, conceptual foundations, and practical experiences with special emphasis on energy systems. Working paper No. 92. Stuttgart: Center of Technology Assessment.

Löfstedt, R. 2005. Risk management in post trust societies. London: Palgrave Macmillan.

Marti, K., Y. Ermoliev, and M. Makowski (eds.). 2010. Coping with uncertainty: Robust solutions. Berlin and Heidelberg: Springer.

Nelson, T.E., Z.M. Oxleay, and R.A. Clawson. 1997. Toward a psychology of framing effects. Political Behavior 19(3): 221-246.

Okada, N. 2018. Adaptive process for SMART community governance under persistent disruptive risks. International Journal of Disaster Risk Science. https://doi.org/10.1007/s13753-018-02047.

Okada, N., J.-L. Na, and L. Fang. 2013a. The Yonmenkaigi System Method: An implementation-oriented group decision support approach. Journal of Decision and Negotiation 22(1): 45-52.

Okada, N., L. Fang, and D.M. Kilgour. 2013b. Community-based decision making in Japan. Journal of Decision and Negotiation 22(1): 57-69.
Pelling, M., C. High, J. Dearing, and D. Smith. 2008. Shadow spaces for social learning: A relational understanding of adaptive capacity to climate change within organisations. Environment and Planning A: Economy and Space 40(4): 867-884.

Reese, S.D., O.H. Gandy Jr. and A.E. Grant. 2003. Framing public life: Perspectives on media and our understanding of the social world. Mahwah, NJ: Lawrence Erlbaum Associates.

Renn, O. 2008. Risk governance: Coping with uncertainty in a complex world. Earthscan: London.

Renn, O. 2015. Stakeholder and public involvement in risk governance. International Journal for Disaster Risk Science 6(1): 8-20.

Renn, O. 2017. Risk governance: Concept and application to systemic risk. In Risk conundrums: Solving unsolvable problems, ed. R.E. Kasperson, 243-259. London and New York: Routledge.

Renn, O., and A. Klinke. 2013. Space matters! Impacts for risk governance. In The spatial dimension of risk: How geography shapes the emergence of riskscapes, ed. D. Müller-Mahn, 1-21. Milton Park and New York: Routledge.

Renn, O. and A. Klinke. 2014. Risk governance. Application to urban planning. ITU Journal of the Faculty of Architecture 11(1): $5-19$.

Renn, O., and A. Klinke. 2016a. Risk governance: Concept and application to technological risk. In Routledge handbook of risk studies, ed. A. Burgess, A. Alemanno, and J.O. Zinn, 204-215. London and New York: Routledge.

Renn, O., and A. Klinke. 2016b. Complexity, uncertainty and ambiguity in inclusive risk governance. In The Routledge companion to strategic risk management, ed. T.J. Andersen, 13-30. Milton Park and New York: Routledge.

Renn, O., A. Klinke, and M. van Asselt. 2011. Coping with complexity, uncertainty and ambiguity in risk governance: A synthesis. AMBIO 40(2): 231-246.

Renn, O., and P.-J. Schweizer. 2009. Inclusive risk governance: Concepts and application to environmental policy making. Environmental Policy and Governance 19(3): 174-185.

Renn, O., and K. Walker. 2008a. Lessons learned: A re-assessment of the IRGC framework on risk governance. In The IRGC risk governance framework: Concepts and practice, ed. O. Renn, and K. Walker, 331-367. Heidelberg and New York: Springer.

Renn, O., and K. Walker (eds.). 2008b. The IRGC risk governance framework: Concepts and practice. Heidelberg and New York: Springer.

Rose, A. 2018. Distributional considerations for transboundary risk governance of environmental threats. International Journal of Disaster Risk Science. https://doi.org/10.1007/s13753-018-02056.

Rowe, G., and L.J. Frewer. 2000. Public participation methods: A framework for evaluation. Science, Technology and Human Values 25(1): 3-29.

Skelcher, C. 2005. Jurisdictional integrity, polycentrism, and the design of democratic governance. Governance 18(1): 89-110.

Stoll-Kleemann, S., and M. Welp (eds.). 2006. Stakeholder dialogues in natural resources management: Theory and practice. Heidelberg and Berlin: Springer.

Thaler, R.H., and C.R. Sunstein. 2009. Nudge: Improving decisions about health, wealth and happiness. New York: Penguin.

Underdal, A. 2009. Complexity and challenges of long-term environmental governance. Global Environmental Change 20(3): 386-393.

Waldrop, M.M. 1992. Complexity: The emerging science at the edge of order and chaos. London: Penguin.

Webster, D.G. 2009. Adaptive governance: The dynamics of Atlantic fisheries management. Cambridge: MIT Press.

Zahariadis, N. 2003. Ambiguity and choice in public policy: Political decision making in modern democracies. Washington, DC: Georgetown University Press. 